\title{
In-situ Observations of Stability of Pd Nanoparticles in the Presence of Reactive Gases
}

\author{
L. Kovarik ${ }^{1}$, A. Genc ${ }^{2}$, A. Karim ${ }^{3}$, J. Szanyi ${ }^{3}$, J.H. Kwak ${ }^{3}$, C.H.F. Peden ${ }^{3}$
}

1. Environmental Molecular Science Laboratory, Pacific Northwest National Laboratory, P.O. Box 999, Richland, Washington 99352 USA

2. FEI company, USA NanoPort, 5350 NE Dawson Creek Drive, Hillsboro, Oregon 97124, USA

3. Institute for Integrated Catalysis, Pacific Northwest National Laboratory, P.O. Box 999, Richland, Washington 99352 USA

Noble-metal catalytic nanoparticles supported on oxide or non-oxide substrates can undergo a number of surface/structural transformations during exposure to elevated temperatures and reactive gas environments. A significant research effort has been devoted in the past to study the interaction of oxygen with supported noble-metals but, despite this effort, the nature and the mechanism of these thermally activated transformations are still debated in the literature. In this work, we will present atomic-level in-situ TEM observations of oxidation of Pd nanoparticles supported by model and high-surface-area substrates. Supported Pd nanoparticles are now well recognized as highly effective catalysts for numerous oxidation reactions including, for example, the oxidation of $\mathrm{CO}$ in automotive exhaust systems, and developing fundamental insights into these thermally activated transformations/processes is needed for future theory informed design.

The in-situ Transmission Electron Microscopy observations were performed with an environmental FEI Titan 80-300 equipped with a CEOS Cs -image corrector operated at $80 \mathrm{kV}$ and $300 \mathrm{kV}$. The imaging was performed in the presence of reactive gases of up to $\sim 10 \mathrm{mbar}$, and the samples were heated with a MEMS-based Aduro ${ }^{\mathrm{TM}}$ Protochips heating holder. Additional ex-situ observations were performed with a probe corrected FEI Titan 80-300.

The first part of the presentation will focus on in-situ imaging of Pd nanoparticles supported on $\gamma-\mathrm{Al}_{2} \mathrm{O}_{3}$ during an elevated temperature oxidation/reduction treatment. Observations in the oxidizing environment and temperatures up to $500{ }^{\circ} \mathrm{C}$ show that a large population of $\mathrm{Pd}$ metallic nanoparticles can become rapidly unstable and dissolve as highly dispersed atomic species. In the reducing environment, the dispersed Pd species re-precipitate as nanoparticles. An example of the phenomena, depicting a series of oxidized and reduced microstructures, is shown in Fig.1. Quantitative evaluation of the particle sizes suggests that the stability of $\mathrm{Pd} / \mathrm{PdO}$ particles in an oxidizing environment can be achieved above a critical size, although some variations are observed for different regions of the sample. The stability of the Pd oxide nanoparticles with respect to the highly dispersed species will be discussed.

The second part of the presentation will focus on atomic-scale analysis of $\mathrm{PdO}$ formation on $\mathrm{Pd}$ nanoparticles $\left(5-15 \mathrm{~nm}\right.$ in size) at temperatures of $400-500{ }^{\circ} \mathrm{C}$ and in a $\mathrm{pO}_{2}$ of $10^{-3}-1$ mbar. It will be shown that $\mathrm{PdO}_{\mathrm{x}}$ formation starts at the $\mathrm{Pd} /$ support interphase and then subsequently grows to encapsulate the rest of the nanoparticles. The very early stages of oxide formation have been observed to cause a strong surface faceting, as shown in Fig.2(b,c). In the following stages of oxidation, a relatively well-defined surface oxide has often been detected, as shown in Fig.2(d,e,f,g), at which point the faceting becomes less pronounced. Analysis of the inter-planar 
spacing and bond distances, as shown in Fig.2h, suggests that this surface oxide is different from $\mathrm{PdO}$. In addition to this surface oxide phase, we will also present evidence of $\operatorname{Pd}_{2} \mathrm{O}$ formation in the early stages of oxidation, and show that a high degree of coherency can be accomplished by misfit dislocations. The detected oxide phases will be placed into perspective with the known Pd surface oxides. Lastly, we will discuss electron beam effects and present examples where high dose electron beam exposure is observed to cause structural transformations [1].

[1] This research is part of the Chemical Imaging Initiative at Pacific Northwest National Laboratory. The work was conducted in the William R. Wiley Environmental Molecular Sciences Laboratory (EMSL), a national scientific user facility sponsored by DOE's Office of Biological and Environmental Research and located at PNNL.

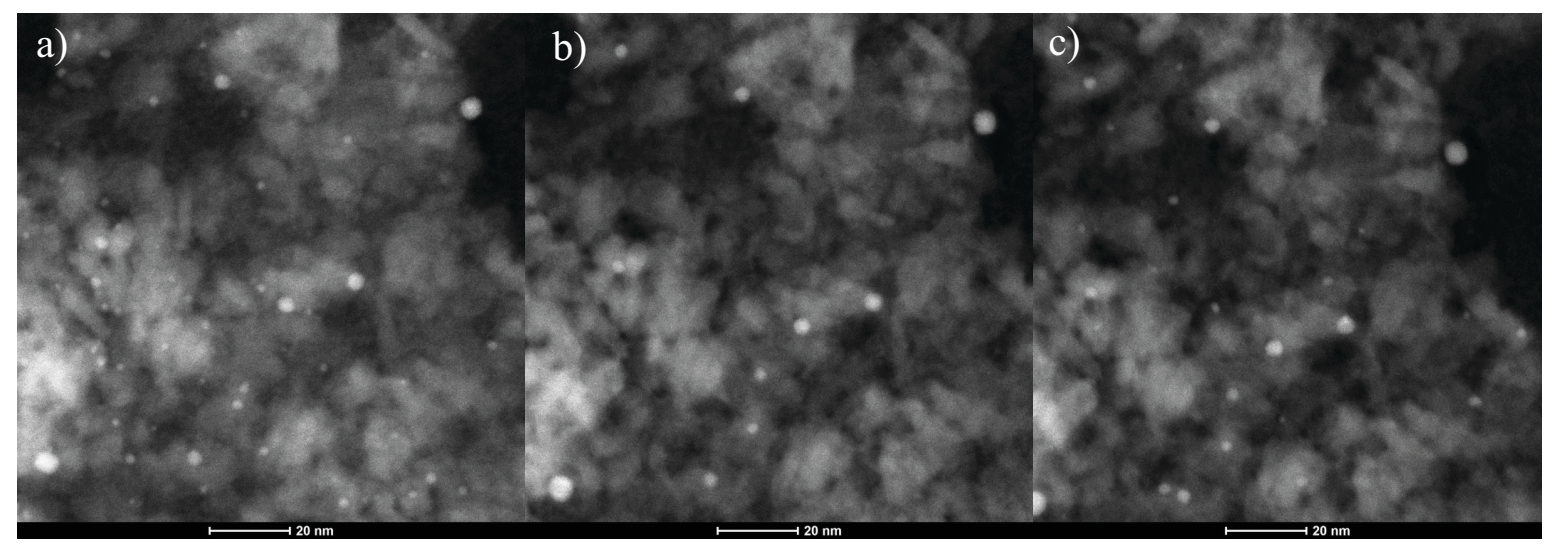

Figure. 1. STEM images of $\mathrm{Pd} / \gamma-\mathrm{Al}_{2} \mathrm{O}_{3}$ catalysts during the course of oxidation and reduction treatments: (a) after reduction at $400{ }^{\circ} \mathrm{C}, 5 \% \mathrm{H}_{2} \sim 3 \mathrm{mbar}$; (b) after oxidation at $500{ }^{\circ} \mathrm{C}, 23 \% \mathrm{O}_{2}$ $\sim 3 \mathrm{mbar}$; and (c) after reduction at $400{ }^{\circ} \mathrm{C}, 5 \% \mathrm{H}_{2} \sim 3 \mathrm{mbar}$.

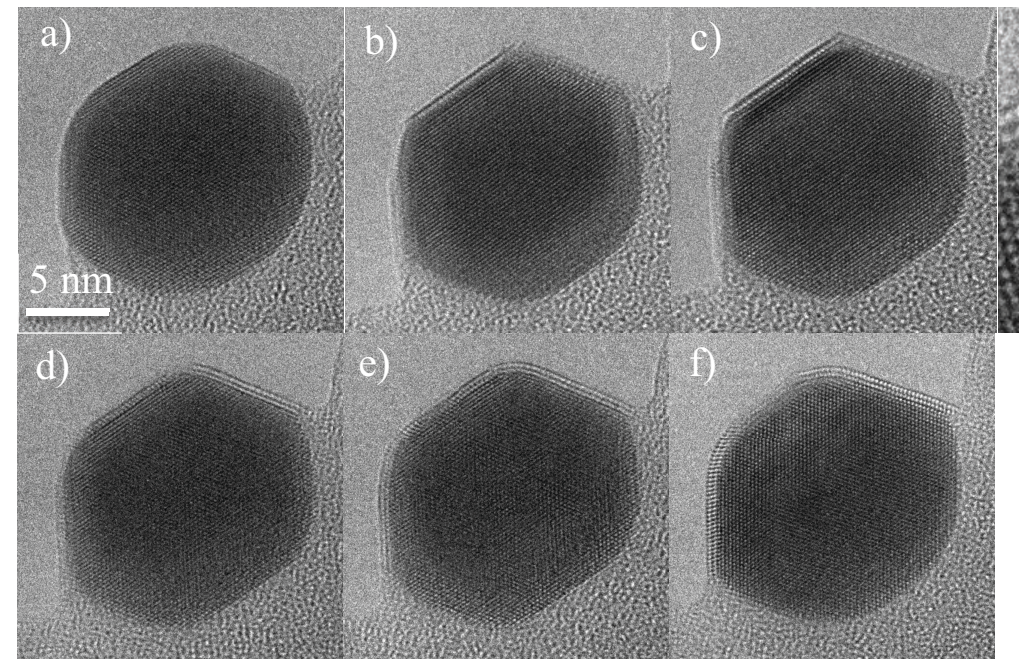

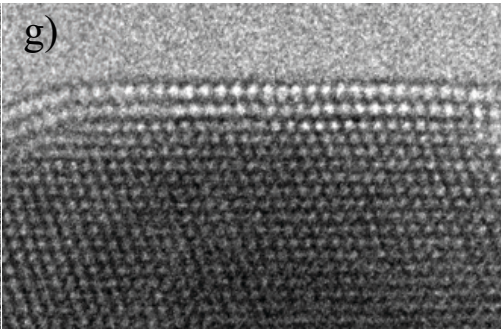

h)

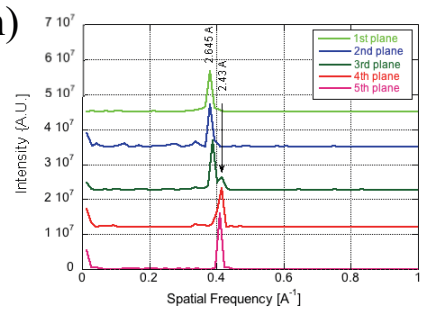

Figure 2. HRTEM imaging of a Pd nanoparticle during oxidation at $500{ }^{\circ} \mathrm{C}$ : (a) initial state; (b-c) strong faceting during the early stages of oxidation; (d-f) further growth of $\mathrm{PdO}_{\mathrm{x}}$; $(\mathrm{g})$ detailed view of the oxide formed on the $\operatorname{Pd}(111)$ surface; and (h) an inter-columnar distance analysis of the surface and subsurface planes. 